\title{
Positive Effects of Sports Events: From Exaggeration to Reality
}

\author{
Keivan Shabani Moghaddam*, Saifulla Shahabzade
}

Faculty of Physical Education, Razi University, Kermanshah, Iran

\section{Email address:}

keivanshabani@gmail.com (K. S. Moghaddam), s.shahabzade@pgs.razi.ac.ir (S. Shahabzade)

\section{To cite this article:}

Keivan Shabani Moghaddam, Saifulla Shahabzade. Positive Effects of Sports Events: From Exaggeration to Reality. American Journal of Sports Science. Vol. 3, No. 3, 2015, pp. 52-56. doi: 10.11648/j.ajss.20150303.13

\begin{abstract}
Although sports events are considered a new field for urban and economic development, besides certain advantages that are obtained by hosting sports events, there are also many dangers. Upon considering the effects of sports events, studies on low-accuracy sports events are heavily relied on. These analyses often exaggerate advantages, underestimate costs and make an improper use of statistics. It appears that there positive effects and especially, financial advantages of sports events have often been exaggerated so that financial profits are often estimated too high, and costs are understated. By considering existing evidences and literature, this study aims to find an answer for this question: How much true are the topics propounded as to the positive effects of sports events?
\end{abstract}

Keywords: Sports Events, Positive Effects, Profit, Cost

\section{Introduction}

In events such as Olympic Games, over ten thousand athletes from over 200 countries compete in 300 sports events, and around 7 million tickets are sold in order that people can watch the games closely. Therefore, big sports events have always been used to improve the image and reputation of the host country. The most popular example is the 1936 Berlin Olympic Games, which was at the service of Hitler's nationalism. From political point of view, sports events bring people together and increase unity, but they may also result in certain protests and demonstrations. From economic point of view, big sports events can lead to economic development. Positive implications of big sports events such as the Olympics have already been proved, but these implications are not limited to this and are also visible in political, social, and cultural dimensions [1]. Events such as the marathon or bike racing result in recognition, improved image, and tour visits for the host city. From the perspective of urban development and the environment, big sports events cause infrastructural and environmental changes in the host city. Big events create an opportunity where major infrastructures such as airports, transport, security, and energy provision are developed in the host city. For example, in the 1960 Rome Olympics, a fresh transport system as well as a new water supply was prepared for the city. In the 1964 Tokyo Olympics, 22 new highways were constructed and the city's water and wastewater system was renovated completely. And London's hosting of the 2012 Olympics led to renovation and improvement of the image of Stanford (a poor London district).

In the recent decades, host cities have made impressive efforts to break the record in terms of the number of audience, building big and luxurious buildings and large conferences. As regards the statement made by Lula da Silva, former prime minister of Brazil, "hosting big events such as the Olympics is a sign of presence among the world's top countries", there are many efforts in non-industrial countries for hosting big global events. However, although benefits and results of hosting these events have always been related, they might also leave deep negative implications. For example, the 1976 Olympics in the Canadian city of Montreal caused enormous financial debt for this city and had no desirable consequence for the city, while the 1992 Barcelona Olympics was a point of developmental jump for this city, which has continued ever since.

Despite great emphasis on the positive impact of sports events, some well-controlled studies have reported contradicting results in this context. For example, it has always been emphasized that hosting sports develops interest in sport among local residents. However, studies have been able to prove this claim, and in fact, interest is only increased in citizens who were already interested. Another example is 
the considerable impact of holding sports events on creating jobs. It has been shown that the majority of these jobs have a temporary nature and concern with holding of sports events, and after that, they are abrogated automatically. Only those jobs that continue after the event (especially in construction, tourism, and leisure) can yield considerable economic implications. The jobs are often a direct result of change in the city's appearance and image and touristic infrastructural improvements. Well aware of the challenges of holding sports events, some authors have suggested that cities evaluate implications from different aspects before bidding to host the Olympics [2]. Although it is perceived that by spending a lot of money, sports spectators and audiences create fruitful economic profit for hosting cities, it could be said that initial evaluations of cost-profit for hosting sports events cannot be highly accurate and in fact, the judgment on whether holding the event is profitable is not possible a priori. For example, it had been stated in the initial evaluation of the World Cup Games hosted by South Africa that the cost of the matches would be 2.6 billion dollars, while the actual cost of the games multiplied this figure, which is very terrible. Although the Atlanta Committee for the Olympic Games predicted 5.1 billion dollars of financial profit and 77 thousand increased employments, but the real number was 35-42 thousand employment [3]. For the Sydney Olympic Games 6.3 billion dollars in profits and 100 thousand new employments had been foreseen. Goodman and Stern predicted a 4 billion dollar impact on the country's economy, and Dentsu Institute for Human Studies had predicted a 24.8 billion dollar profit for Japan and an 8.9 million dollar profit for South Korea. Nonetheless, none of these actually happened in reality, leading to these predictions getting criticized by many experts [2]. Some authors believe that exaggerations are made in showing the real effects of events, because many of these studies are conducted by people who are very fond of holding such events.

\section{Discussion Regarding Actual Effects of Sports Events}

By examining existing literature, this study seeks to identify the realities concerning the impacts of sports events, without falling in the abyss of exaggeration so that in a reasonable manner and by spending rational costs, the occurrence of great risks that even some developed countries have suffered could be minimized. By examining studies addressing the impacts of sports events and providing evidence regarding the methodologies used in the literature, places, and legacies remained from sports events, employment, tourism, local residents' lifestyle, multiplier factor, the environment, etc., this research attempts to investigate positive impacts of sports events regardless of any type of exaggeration.

Methodology Errors Concerning Predictive Studies:

Most studies regarding event effects (based on which investments are made) are predictive and unreal. They estimate economic impacts in two ways: 1) The effect of building infrastructures such as sports facilities, and 2) Set of activities happing during the event (e.g. estimating the number of participants, number of visitors' residence days and their average spending) [4]. In the second case, figures are combined to produce a direct economic impact. Nonetheless, the direct effect estimation method has been criticized by many experts. For example, since most customers have limited budget, the cost spent for the event e.g. ticket purchase, substitutes spending in other activities within the local economy such as cinemas, parks, or concerts. Also, many of participants only attend stadiums and don't make a purchase from local people. Therefore, in order to make studies regarding big events such as the Olympics valid, surveys must be carried out on the event participants, incorporating questions regarding their residence [5].

Constructions, More of Expense or Profit?

Building new sports facilities and stadiums and improving infrastructures such as communication systems, residence facilities, and traffic hub network is necessary for successful organization of sports events. Given these huge expenses, it comes as no surprise that most cities that hosted big events such as the Summer Olympic Games were in developed countries. From among the 25 periods of the Olympics between 1894 and 2004, it has been organized 14 times in the Western European countries and 7 times in the USA, Canada, and Australia. The games held in Mexico City and Seoul (in 1968 and 1988, respectively) were the only matches held in developing countries. Besides huge investment in building sports facilities, Barcelona (1992) and Seoul (1988) in fact used these games to improve all their urban infrastructures. This shows the determination of event organizers to create long-term opportunities that cover short-term costs. Even Atlanta (1996) needed just a few stadiums to complete its existing infrastructures when it spent about 600 million dollars (Baade \& Matheson, 2004). This also applies to the FIFA World Cup. FIFA has obliged host countries to have at least eight and preferentially ten modern stadiums with the audience capacity of 40 to 60 thousand people. For the 2002 World Cup, South Korea spent 2 billion dollars to build ten new stadiums and Japan spent 4 million dollars to build seven new stadiums and renovate three existing ones. Additionally, it is clear that other costs are also on the rise. For example, Salt Lake City, host of the 2002 winter games, spent over 300 million dollars merely on security, and Greece, host of the 2004 summer games, spent over 1 billion dollars on security [6]. In addition to these costs, about 1 billion dollars must be considered as practical cost of a big event. Findings of some researchers (Coates \& Humphreys, 1999; Noll \& Zimbalist, 1997) have shown that there is no correlation between construction of sports stadiums and economic development, although most studies consider construction of stadiums more of profit than cost [7, 8]. Despite the fact that new constructions can be considered useful, it is necessary to also consider the burning of opportunities, because local expenditure on such projects means reduced expenditure in other public services, 
increased governmental debts, or increased taxes. Is the return on investment in a sports stadium able to compensate for resource usage in other projects?

Uselessness of remained facilities:

With regards to the construction of sports facilities, that how these newly built facilities will be used is extremely important. There is not much that can be done with an empty soccer stadium. After the 2002 World Cup, only five of ten stadiums in South Korea witnessed orderly sports events. Furthermore, in a stadium of 40 to 60 thousand people, just about 3 thousand spectators are professional soccer fans. Even in Japan, with the more advanced soccer league of JLeague, average number of spectators is only 16 thousand people. It is clear that sports events offer a luxurious product, and demand for using the residence gradually declines after the event. Therefore, especially for developing countries, there is a risk of infrastructures related to the event turning into a big issue. For example, in the 2003 All-Africa Games, the government of Nigeria spent about 300 million dollars on building a 60 thousand-people stadium, whereas the country was suffering from such issues as fuel shortage, frequent power outages, bad roads, and a high crime rate. Another example of hidden costs is the continuous maintenance costs of big stadiums. Other divisions like hotel housekeeping industry might also be affected by long-term costs. In order to accommodate the high number of visitors during an event, hotels have to build new parts. But when the event is over, demand for these places is reduced, exerting the high cost of maintenance on hotel owners [9].

Employment via Construction:

The above issue also applies to constructions, which is, in turn, another suspected area in the studies pertaining to economic impact (for example, Siegfried \& Zimbalist reported that most workers are residents of non-local districts). Findings of some authors (Coates \& Humphreys, 1999; Noll \& Zimbalist, 1997) showed that there is no correlation between construction of sports stadiums and economic development $[7,8]$. If the host city has a lot of unemployed people, stadium building can be seen as an employment opportunity. Nonetheless, this cannot be considered as mere profit, because in fact just a number of workers have been transferred from one job to another. Researchers consider this as if the government employs a group of people to dig a hole and then another group to fill the hole. Employment resulted from construction is often temporary. For example, during the World Cup in South Africa, employment soared and migrants were absorbed from rural areas, whereas unemployment of the citizens increased after the games. Baade and Matheson found in a study they did after 1996 Atlanta games that recruits in these games did not exceed 42 thousand which is far less than 77 thousand as estimated by the organizing committee. Increased employment in the 1984 Los Angeles games was about 5 thousand people, but the result of studies showed that no net employment output had been resulted from the games [3]. Of course, these results can be due to the fact that Los Angeles did not put considerable capital in sports infrastructures and made the most use of existing facilities.

Misconception in the Analysis of Foreign Visitors:

Mere consideration of foreign visitors can lead to exaggerating figures. Some visitors might be accommodated in their relatives' homes. On the other hand, when not going to watch the event, the visitor spends his/her money in other attractions of the city. For instance, if someone has a short trip to China for business and goes one night to watch a sports event, his net cost for the event will only be the ticket price, whereas he has spent most of his money in financial affairs pertaining to hotel residence, restaurants, and the like. Therefore, what is reported in event impact studies regarding direct financial effect is estimated too high, because the money an individual has spent in hotel, restaurants, etc. is considered a sports event profit [10]. Additionally, another phenomenon that has not been considered deals with the direct effect of time change, which occurs when a visitor intends to travel to the city in question, but they schedule their trip in a way that they arrive during the sports event. Therefore, the event actually had no effect on destination selection and the spent money cannot be linked to the sports event [11]. Of course, for big events such as the Olympics, a large number of visitors from different countries specifically travel for the event, leading to more conformity with net and raw incomes.

Changing Lifestyles of Local Residents:

Studies of event effect often ignore local residents who live in the area but are not participating in the event. In fact, many of local residents greatly change their expenditure style in order to stay safe from paying extra money-due to inflation caused by visitors' entry. Baade and Matheson (2004) stated that the important problem in event effect studies has nothing to do with direct costs, but it concerns information deficiency regarding economic activity style of those who don't take part in the event. Local residents don't often benefit from growth of tourists during the event.

Banishing the population:

Since most big events such as the Olympic Games are held in areas liked by tourists, negative outputs caused by the event such as overcrowding might discourage typical tourists from visiting the city during the event. If the event's nearby restaurants and hotels are busy, sports visitors might banish normal tourists from the area, leading to a net impact less than predicted values. A good example in this context is related to the South Korea Soccer World Cup, in which it became known that the total number of foreign visitors during that time was equal to that of the corresponding period in the previous year. Also, USA Today reported concerning customers' expenditure in 2002 that although products like sports goods had a good sale, some hotels and recreational places had decline in the number of customers. Existing information and field observations showed that the Atlanta 1996 Olympics had a similar effect in banishing crowds. According to the results of French and Disher (1997), in parts of the city close to the Olympic Park, many hotels and restaurants reported a lower sale during the games than usual [12]. Even stores located within a 150 mile distance reported 
a weaker business in summer 1996.

Pressure on Poor and Underprivileged People:

Despite the numerous long-term advantages of urban infrastructural improvement projects (For example, Barcelona constructed new districts and roads, repaired old routes, and reduced the city traffic), these projects leave negative effects on the underprivileged people. As regards residence, Pillai and Bass reported by evaluating the 2010 World Cup that increase in property price around the event holding place resulted in increased rentals, so that the local poor people were no longer able to pay them. Although the region benefited from thriving real-estate business, people who were supposed to benefit from it were dismissed. Furthermore, urban renovation might lead to redistribution of people, driving the people inhabiting the event holding area to other regions, which in turn leads to poverty and social issues. It has been reported that 700 thousand people had to leave their homes in the 1988 Seoul Olympics and it had been estimated that over the last 20 years, over two million people have had to leave their houses because of the Olympics. This issue was especially most apparent globally in the months before the 2014 Brazilian Soccer World Cup, when the Brazilian government demolished homes of many people in poor districts with the purpose of improving the image and appearance of the city, and encountered an enormous flood of demonstrators.

Misuse of Multipliers:

One of the toughest problems in economic forecast concerns misusing the multiplier factor. Direct expenditures estimated from the event are used to achieve indirect results that are less often subject to exaggeration. The economic multiplier that is usually used in economic forecast is calculated according to complex formulae, modeling the relationship between industries in the area. But, Matheson has suggested that during a great sports event, these relationships are less probable to be established, resulting in an inaccurate multiplier. A researcher must differentiate between whether visitors spend their money within the local economy, or on hotel rooms and restaurants [4]. Regarding the latter case, the profit obtained during the event is not flown into the local economy, but is sent to stakeholders all around the world.

Lack of Considerable Revenue Generation for the Local Economy:

Big events such as the World Cup and the Olympic Games are to a great extent autonomous. That is, financial sponsors and many companies are allowed to access the places of holding the event, whereas local businesses don't have this permission [13]. This results in these events being a type of independent economy. That is to say, most of the financial revenue is given to companies which are not main elements of the local economy. Economic forecasts only use inputoutput models, which don't consider the final destination of money deposits.

Safety/Security-Related Costs:

Although it is clear that the costs related to establishing security for sports events are very high and for various reasons they have been on the rise during the recent years, different countries avoid mentioning its accurate value [2]. The cost of establishing security in the 2004 Athens Olympic Games was estimated at about 1.08 billion euros, with 40000 people responsible for it [15]. De Nooij et al (2012) estimated the cost of general security for the 2006 German World Cup Games at 450 million euros [14]. Of course, some newspapers estimated this cost at about 1 billion dollars, which is not reliable due to uncertainty [2].

Cost Pertaining to Frustration in Hosting:

Bidding to host big sports events requires considerable investing, which is, of course, ignored when evaluating the economic impact of the event. Chicago's unsuccessful attempt to host the 2016 Olympic Games cost the city more than 100 million dollars [16]. An Australian senate representative had reported a 48.8 million-dollar cost for unsuccessful bidding of hosting the 2022 World Cup Games [17]. The probability of failure in securing the hosting of the events is also of significant costs that have to be considered [14].

Negative Environmental Effects:

Organizing big sports events has significant environmental effects on the host city before, during, and after the event, and these effects exert a pressure on it during construction, transport, and waste discharge. Organizing big sports events requires a sufficient number of big facilities, and hence, intense construction and renovation is conducted, imposing abundant cost on the environment. Energy and property intended to be used for construction and design of roads and transport routes will result in the threat of annihilation of farm lands, natural resources, and forests and parks. Development of the host city will lead to pollution of the air, and water and soil, thus threatening the health of human ecosystems. Climate change caused by increased toxic gases such as carbon monoxide, carbon dioxide, and nitrogen oxides will lead to decreased agricultural products, increased pollution, forests destruction, increased environmental temperature, annihilation of bio-species and therefore, ecosystem destruction.

Intangible Benefits, a Double Edged Sword:

Although economic benefits for hosting enormous events is questionable, there are intangible reasons why countries want to host these events despite problems. One reason concerns the perceived situation of the city, leading the city to ascend within the hierarchy of world's cities. Given the process of globalization, this can augment the tourism industry of the region. Obviously, one of Beijing's goals to host the 2008 Olympics was to rank among the 10 major cities of the world and to outpace its Asian rivals i.e. Tokyo, Singapore, and Hong Kong. Besides, other advantages such as self-confidence, national pride and dynamics have also been mentioned, and therefore, holding big events brings prestige and identity to the region. For the Chinese, the 2008 Olympics was of little importance in sports terms and was further used as a demonstration of China's economic and political growth. In fact, the organizer for the games announced that the Olympics was an opportunity for China to show how free, democratic, civilized, friendly, and orderly it 
is. Of course, in a pessimistic way, these games can be compared with political exhibition in the 1936 Berlin Olympics and the 1938 Italy World Cup.

\section{Conclusion}

It is often believed that hosting and organizing sports events yields significant benefits such as changing urban design, changing existing physical environment, exhibiting the city and its culture, improving climate, development of roads and rail transport system, better governmental decisions, increased number of tourists and occupations, building new sports facilities, national unity and cooperation. Nonetheless, it seems that the idea that a multi-week sports event can leave sustainable impacts on the host city has to be looked at suspiciously. As a matter of fact, the advantages are not as big as they look and there are many problems and obstacles in achieving them. The major reason why most people feel happy about organizing and hosting sports events and assume that might be in favor of their community is that their authorities and decision makers usually start renovating the city and improving transport systems as well as renovating sports facilities. Nonetheless, in most cases, benefits are not as much as people expected.

Clearly, sports events highly rely on sports effect studies with low accuracy, which exaggerate benefits in their analyses, while underestimating the costs and misusing multiplier factors. Although certain benefits are obtained by hosting sports events, there are also many dangers. Before making decisions for any conduct or expenditure, the new structures that are to be designed must be integrated with the context and economy of the city and also, the event's legacy has to be planned. Such an event prepares the ground for proper attempts in maintaining national capital.

\section{References}

[1] Whitson, D. and J. Horne (2006) 'Underestimated Costs and Overestimated Benefits? Comparing the Outcomes of Sports Mega-Events in Canada and Japan', in J. Horne and W.

[2] De Nooij, M. Van den Berg, M (2013) The bidding paradox: why rational politicians still want to bid for mega sports events, Tjalling C. Koopmans Research Institute, Utrecht School of Economics.

[3] Baade, R. and V. Matheson (2002) 'Bidding for the Olympics: Fool's Gold?' in C. P. Barros, M. Ibrahimo and S. Szymanski (eds.)
[4] Matheson, V. (2006) 'Economic Impact Analysis', in W. And reff and S. Szymanski (eds.) Handbook on the Economics of Sport, Cheltenham: Edward Elgar.

[5] Baade, R. and V. Matheson (2004) 'Mega-sporting Events in Developing Nations: Playing the Way to Prosperity?', South African Journal of Economics, 72, 5, 1084-1095.

[6] Baade, R. (2006) 'The Economic Impact of Mega-sporting Events', inW. Andreff and S. Szymanski (eds.) Handbook on the Economics of Sport, Cheltenham: Edward Elgar.

[7] Coates, D. and B. Humphreys (1999) 'The Growth Effects of Sport Franchises, Stadia and Arenas', Journal of Policy Analysis and Management, 18, 4, 601-624.

[8] Noll, R. and A. Zimbalist (1997) 'The Economic Impact of Sports Teams and Facilities', in R. Noll and A. Zimbalist (eds.) Sports, Jobs\& Taxes: The Economic Impact of Sports Teams and Stadiums, Washington, DC: Brookings Institution Press.

[9] Humphreys, B. and S. Prokopowicz (2007) 'Assessing the Impact of Sports Mega-events in Transition Economies: EURO 2012 in Poland and Ukraine', International Journal of Sport Management and Marketing, 2, 5/6, 496-509.

[10] Siegfried, J. and A. Zimbalist (2002) 'A Note on the Local Economic Impact of Sports Expenditures', Journal of Sports Economics, 3, 4,361-366.

[11] Crompton, J. L. (1995) 'Economic Impact Analysis of Sports Facilities and Events: Eleven Sources of Misapplication', Journal of Sport Management, 9, 1, 14-35.

[12] French, S. and M. Disher (1997) 'Atlanta and the Olympics: A One-year Retrospective', Journal of the American Planning Association, 63, 3, 379-392.

[13] Owen, J. (2005) 'Estimating the Cost and Benefit of Hosting Olympic Games: What can Beijing Expect from its 2008 Games?', The Industrial Geographer, 3, 1, 1-18.

[14] De Nooij, M. de, M.R. van den Berg, C.C. Koopmans (2012) Bread or Games? a Social Cost-Benefit Analysis of the World cup bid of the Netherlands and the Winning Russian bid. Journal of Sports Economics. Forthcoming.

[15] Cost of Athens 2004 Olympics. Press Office. Washington, DC.13 November.

[16] Zimbalist, A. (2010) Is It Worth It? Hosting the Olympic Games and other mega sporting events is an honor many countries aspire to - but why? Finance \& Development March 2010, pp 8-11.

[17] Reuters (2011). Australia senator demands FIFA "refunds" bid money,(http://www.reuters.com/article/2011/05/30/us-soccerfifa-australia-idUSTRE74TOLT20110530. 